\title{
The next unknown for patients with metastatic disease: optimal surveillance after palliative radiation therapy
}

\author{
Kathryn R. Tringale, Fumiko Chino, Charles B. Simone II, Divya Yerramilli \\ Department of Radiation Oncology, Memorial Sloan Kettering Cancer Center, New York, NY, USA \\ Correspondence to: Kathryn R. Tringale. Memorial Sloan Kettering Cancer Center, 1275 York Ave Box 22, New York, NY 10065 , USA. \\ Email: tringalk@mskcc.org.
}

Submitted Mar 31, 2021. Accepted for publication Jun 10, 2021.

doi: 10.21037/apm-21-771

View this article at: https://dx.doi.org/10.21037/apm-21-771

Radiation therapy is an effective tool in the palliation of patients with metastatic cancer (1), playing a role in controlling bleeding (2), alleviating pain from bone and soft tissue metastases (3), preventing pathologic fractures, relieving airway or bowel obstruction (4), and preventing neurological compromise from brain or spinal metastases (5). The indications for radiation therapy continue to expand as patients with metastatic disease live longer (6). However, the objectives of palliative radiation have not wavered since 1964, when Parker introduced a unique approach to treatment: "When the initial objective of radiation therapy is palliation, new ground rules must be applied. Possible serious complications or even slowly self-limiting adverse effects of treatment are no longer acceptable. Overall treatment time must be short. Cost must be minimized. Convenience of treatment must be considered" (7).

Since that time, the research and clinical emphases in the palliative care setting have focused on ensuring effective, yet shortened, treatment courses and avoiding overuse (2). Multiple clinical trials have been conducted to investigate outcomes comparing single and multifractionated treatments, often concluding that single fraction treatments of bone metastases can provide equivalent pain relief. This finding has culminated in ASTRO's Choosing Wisely campaign advocating for "strong consideration" of single fraction treatment (8). In a parallel effort to shorten treatment, dose-escalation has been made possible with techniques such as stereotactic body radiation therapy (SBRT), resulting in both excellent pain control and durable local control in an era of prolonged survival in metastatic cancer. Still, an increasing number of patients outlive the duration of their initial radiation therapy beneficial effects, or they may develop new metastatic lesions, ultimately becoming candidates for an additional course of radiation therapy. Consideration of reirradiation is important as it can be an effective strategy with minimal toxicity in the palliative setting $(9,10)$.

Patients with metastatic disease are experiencing increasing survival due to developments in systemic therapy, the more widespread use of targeted therapy and immunotherapy, and improvements in supportive and palliative care. As we continue to better understand the natural history of oligometastatic and oligoprogressive disease, along with the increasing role of retreatment of patients with metastatic cancer, it is now time to focus on optimizing the surveillance of these patients. For patients with brain and spine metastases, the 2020 National Comprehensive Cancer Network (NCCN) guidelines have detailed surveillance recommendations including explicit imaging intervals (11). However, for patients with nonneurologic indications for palliative radiation, such as non-spine bone metastases, tumor-induced bleeding, or obstructive central airway disease, guidelines are currently lacking. The NCCN guidelines for palliative care describe an important framework for necessary ongoing reassessment after palliative care interventions (12), keeping the focus on patient-centered outcomes of symptom control and quality of life. Yet, actionable specifics are lacking, and optimal repeat imaging and follow-up assessment schedules are not provided.

Thus, at present, practice patterns (e.g., frequency, interval, and format of post-treatment visits) are varied and left up to the provider and/or patient. It is important to ensure adequate follow-up after radiation treatment to 
enable early identification of possible radiation side effects or inadequate treatment response, facilitating symptom management strategies and salvage or reirradiation interventions, respectively. Early and regular assessments may also prevent subsequent hospitalizations and potential suffering, and in some cases allow for the delivery of further intervention to prolong survival or improve quality of life. Importantly, in a qualitative analysis of medical oncology focus groups, it has become apparent that many medical oncologists do not view radiation oncologists as having a role or expertise in end-of-life care (13). Therefore, a continued involvement of radiation oncologists demonstrates a commitment to our patients and an increasing role in end-of-life care. These efforts must be balanced by the potential burden they may have on the patient and health care systems. Frequent imaging and clinic visits can lead to both financial and quality of life toxicity in this particularly vulnerable population, with a risk of unnecessary expenditures, transportation, emotional stress, or overutilization of resources (14). Financially, endof-life costs in the last year of life alone have been reported to range from $13-25 \%$ of all Medicare costs (15).

Given the equipoise between patient burden and ongoing clinical and radiographic follow-up, we evaluated practice patterns at our institution for patients treated from 20172019. Among 3,082 patients treated with radiation therapy for bone metastases, $49 \%$ had follow-up with radiation oncology and 79\% underwent imaging within 3 months of radiotherapy completion. Interestingly, there was similar radiation oncology-specific follow-up between patients who underwent SBRT vs conventionally fractionated RT ( $55 \%$ vs. 57\%, respectively); however, a higher proportion of patients who received SBRT underwent imaging within 3 months ( $84 \%$ vs. $72 \%$ ), which may reflect a variety of factors such as performance status, prognostic information, treatment intent, and role of radiation oncologist in the patient's care (more central vs. consultant). Post-treatment imaging in the metastatic patient population may be obtained for a variety of reasons-to assess for tumor response, toxicity, restaging, evaluation of new symptoms or signs-and by a variety of physician specialists given the multidisciplinary involvement in metastatic cancer care. Results of these scans can also introduce potential for reirradiation or treatment of a new site entirely. In our patient cohort, most $(74 \%, 2,266)$ patients survived to 3 months after radiation therapy completion and a minority of those patients $(18 \%, 397)$ initiated another radiation treatment within 3 months. While capturing an opportunity for a subsequent radiation treatment may be beneficial (i.e., prophylactic in the setting of impending fracture), radiation treatment of asymptomatic (even high risk) lesions has an unclear benefit and is currently undergoing prospective investigation (16). Thus, the value of scheduled imaging for the purposes of surveillance is unclear and may put patients at a high risk of undue burden and financial toxicity, especially with long and expensive tests like MRI. On average at our institution, appointment times for spine and brain MRI are 59 and 56 minutes, respectively, whereas CTs and X-rays take considerably less time (both 20 minutes). These are minimum time estimations and do not include time spent waiting or the burden of travel. This point is particularly important in the end-of-life setting, where unnecessary burden must be balanced with the potential for early intervention, and all of these decisions must be governed by the patient's goals of care, which may continuously evolve throughout their disease course.

There are evolving strategies for long-term physician involvement in patient-centered care for those with metastatic disease that may avoid the potential burdens of increased appointments. Time burden affects both patients, who are often in pain and/or have other physical limitations, and families, who may also have financial stresses from missed work or travel/parking costs $(17,18)$. For example, several initiatives have been done to implement formal telephone programs to enable outcome assessments of symptom relief after palliative radiotherapy, demonstrating feasibility and comparable prospective data collection $(19,20)$. In the era of the COVID-19 pandemic, the utilization of telemedicine has become critical for continuing radiation oncology care (21), and it has the potential to save patients' time and money (22). If in line with the patient's needs, telehealth surveillance may offer opportunities to discuss and further refine goals of care, but we cannot forget to integrate human connection and the medical, psychological, and spiritual needs of our patients. It is important to keep in mind that these remote visits may not be appropriate for all patients. In addition to physical exam limitations, different patient backgrounds, cultural preference, and financial and emotional support systems may drive the decision for in-person versus telehealth follow-ups.

Ultimately, this is a challenging patient population to study given its heterogeneity and competing risks, with treatment approaches and follow-up further complicated by the spectrum of treatment intent from purely palliative to potentially life-prolonging - a distinction further blurred 
by the complexity of accurate prognostication. However challenging, this uniquely vulnerable population is growing and deserves expert attention; open and honest assessment of goals of care from radiation treatment is paramount. While consensus is appreciated for patient consistency and promoting high value care, we acknowledge that blanket consensus will not be adequate, as two patients with the same histology, treatment site, and dose may have completely different values or goals of care. A potential approach could be for patients with frequent medical oncology follow-ups to "see" a radiation oncologist remotely with telehealth on an as-needed basis, while those with pain complaints and multifocal metastatic disease could have a more structured in-person follow-up to evaluate for potential additional palliative interventions.

Therefore, it is essential that we identify current practices in the post-palliative radiation treatment setting. Are we over-imaging or under-following patients after radiation treatment of metastatic disease? The radiation oncologist has the opportunity to play a critical role in the care team devoted to optimizing a patient's quality of life at a time when they are most in need. Appreciation and recognition of this growing patient population has further solidified palliative radiation therapy as a subspecialty of radiation oncology, with the advent of dedicated inpatient services and departments with expert practitioners globally. Yet, we must carefully navigate this delicate balance of supportive versus burdensome care in this vulnerable patient population.

\section{Acknowledgments}

Funding: None.

\section{Footnote}

Provenance and Peer Review: This article was commissioned by the editorial office, Annals of Palliative Medicine. The article has undergone external peer review.

Conflicts of Interest: All authors have completed the ICMJE uniform disclosure form (available at http://dx.doi. org/10.21037/apm-21-771). CBS II serves as the Editorin-Chief of Annals of Palliative Medicine. The other authors have no conflicts of interest to declare.

Ethical Statement: The authors are accountable for all aspects of the work in ensuring that questions related to the accuracy or integrity of any part of the work are appropriately investigated and resolved.

Open Access Statement: This is an Open Access article distributed in accordance with the Creative Commons Attribution-NonCommercial-NoDerivs 4.0 International License (CC BY-NC-ND 4.0), which permits the noncommercial replication and distribution of the article with the strict proviso that no changes or edits are made and the original work is properly cited (including links to both the formal publication through the relevant DOI and the license). See: https://creativecommons.org/licenses/by-nc-nd/4.0/.

\section{References}

1. Konski A, Feigenberg S, Chow E. Palliative radiation therapy. Semin Oncol 2005;32:156-64.

2. Lok BH, Jiang G, Gutiontov S, et al. Palliative head and neck radiotherapy with the RTOG 8502 regimen for incurable primary or metastatic cancers. Oral Oncol 2015;51:957-62.

3. Hartsell WF, Scott CB, Bruner DW, et al. Randomized trial of short- versus long-course radiotherapy for palliation of painful bone metastases. J Natl Cancer Inst 2005;97:798-804.

4. Sundstrøm S, Bremnes R, Aasebø U, et al. Hypofractionated palliative radiotherapy (17 Gy per two fractions) in advanced non-small-cell lung carcinoma is comparable to standard fractionation for symptom control and survival: A national phase III trial. J Clin Oncol 2004;22:801-10.

5. Hoskin P, Misra V, Hopkins K, et al. SCORAD III: Randomized noninferiority phase III trial of singledose radiotherapy (RT) compared to multifraction RT in patients (pts) with metastatic spinal canal compression (SCC). J Clin Oncol 2017;35:18.

6. Caswell-Jin JL, Plevritis SK, Tian L, et al. Change in Survival in Metastatic Breast Cancer with Treatment Advances: Meta-Analysis and Systematic Review. JNCI Cancer Spectr 2018;2:pky062.

7. Parker RG. Palliative Radiation Therapy. JAMA 1964;190:1000-2.

8. Chow E, Zeng L, Salvo N, et al. Update on the Systematic Review of Palliative Radiotherapy Trials for Bone Metastases. Clin Oncol (R Coll Radiol) 2012;24:112-24.

9. van der Linden YM, Steenland E, van Houwelingen HC, et al. Patients with a favourable prognosis are equally palliated with single and multiple fraction radiotherapy: 
Results on survival in the Dutch Bone Metastasis Study.

Radiother Oncol 2006;78:245-53.

10. Jeremic B, Shibamoto Y, Igrutinovic I. Second single 4 Gy reirradiation for painful bone metastasis. J Pain Symptom Manage 2002;23:26-30.

11. NCCN Clinical Practice Guidelines: Central Nervous System Cancers. National Comprehensive Cancer Network. Available online: https://www.nccn.org/ professionals/physician_gls/default.aspx. Published 2020. Accessed December 21, 2020.

12. NCCN Clinical Practice Guidelines: Palliative Care. National Comprehensive Cancer Network. Available online: https://www.nccn.org/professionals/physician_ gls/pdf/palliative.pdf. Published 2019. Accessed December 21, 2020.

13. Gross JP, Kruser JM, Moran MR, et al. Radiation Oncologists' Role in End-Of-Life Care: A Perspective From Medical Oncologists. Pract Radiat Oncol 2019;9:362-70.

14. Manohar P, Ramsey S, Shankaran V. Economic Impact of Imaging Overutilization in Cancer Care. J Am Coll Radiol 2020;17:137-40.

15. Duncan I, Ahmed T, Dove H, et al. Medicare Cost at End of Life. Am J Hosp Palliat Care 2019;36:705-10.

16. Rosen DB, Benjamin CD, Yang JC, et al. Early palliative radiation versus observation for high-risk asymptomatic

Cite this article as: Tringale KR, Chino F, Simone CB 2nd, Yerramilli D. The next unknown for patients with metastatic disease: optimal surveillance after palliative radiation therapy. Ann Palliat Med 2021;10(7):7153-7156. doi: 10.21037/apm-21771 or minimally symptomatic bone metastases: study protocol for a randomized controlled trial. BMC Cancer 2020;20:1115.

17. Bange EM, Doucette A, Gabriel PE, et al. Opportunity Costs of Receiving Palliative Chemotherapy for Metastatic Pancreatic Ductal Adenocarcinoma. JCO Oncol Pract 2020;16:e678-87.

18. Rocque GB, Williams CP, Ingram SA, et al. Health carerelated time costs in patients with metastatic breast cancer. Cancer Med 2020;9:8423-31.

19. Chow E, Fung KW, Bradley N, et al. Review of telephone follow-up experience at the Rapid Response Radiotherapy Program. Support Care Cancer 2005;13:549-53.

20. Haddad P, Wilson P, Wong R. The success of data collection in the palliative setting - telephone or clinic follow-up? Support Care Cancer 2003;11:555-9.

21. Zhang H, Cha EE, Lynch K, et al. Radiation Oncologist Perceptions of Telemedicine from Consultation to Treatment Planning: A Mixed-Methods Study. Int J Radiat Oncol Biol Phys 2020;108:421-9.

22. Shaverdian N, Gillespie EF, Cha E, et al. Impact of Telemedicine on Patient Satisfaction and Perceptions of Care Quality in Radiation Oncology. J Natl Compr Canc Netw 2021. [Epub ahead of print]. doi: 10.6004/ jnccn.2020.7687. 